\title{
Learning with portable digital devices in Australian schools: 20 years on!
}

\author{
C. Paul Newhouse
}

Received: 30 August 2013/Accepted: 7 December 2013/Published online: 22 December 2013

(C) The Australian Association for Research in Education, Inc. 2013

\begin{abstract}
Portable computing technologies such as laptops, tablets, smartphones, wireless networking, voice/stylus input, and plug and play peripheral devices, appear to offer the means of finally realising much of the long heralded vision for computers to support learning in schools. There is the possibility for the technology to finally become a ubiquitously invisible component of the learning environment, empowering children to attempt feats well beyond their current capabilities. These technologies are finding a place in many schools, and there has now been over two decades of research conducted into their use in schools. What is now known about implementing portable computing technologies in schools? What should educational leaders take from this research before making decisions about the technologies used in schools?
\end{abstract}

Keywords Mobile learning - Computer supported learning environments · Educational technology $\cdot$ Computers in schools

\section{Introduction}

It has been 20 years since I started researching the first 1-to-1 portable computer program in a Western Australian (WA) school. At the time I thought that within 10 years this would be typical for all our secondary schools, but it has taken 20 years to get to what appears to be the tipping point (Greaves and Hayes 2008). Of course, the use of computers in schools goes back to the beginning of my teaching career in the 1970s, but it wasn't until computers could be carried around that I was convinced that they could play a central role in improving teaching and

C. P. Newhouse $(\square)$

School of Education, Edith Cowan University, 2 Bradford Street, Mount Lawley,

WA 6050, Australia

e-mail: p.newhouse@ecu.edu.au 
learning. There have always been visionaries who have demonstrated the powerful ways that digital technologies could support learning, but this has generally not been realised in our schools (e.g. DeCorte 1990; Papert 1980). As the technology became more portable and powerful, and less costly, this dissonance was increasingly debated; typically becoming more about implementation strategies and changes to schooling and teaching, rather than the technology itself (e.g. Bebell and Kay 2010; Dede 2008; Ertmer and Ottenbreit-Leftwich 2013; Weston and Bain 2010).

Some Australian schools were early adopters of portable computing, and provided early research into what became known as, laptop or 1-to-1 programs (e.g. Rowe 1993; Shears 1995). In many ways this culminated in 2008 when the Australian government funded secondary schools, or school systems, to provide a computer per student; many used the funds to provide portable computing (Howard and Carceller 2010). Personally, I have been fortunate to be able to conduct a substantial amount of research from the beginning, including from 2003 the first 1-to-1 program at a WA government secondary school (Newhouse 1998, 2008). This paper discusses the continuing rationale for the use of portable/mobile computing systems in schools, and what we have learned over the past 20 years that can guide our future decisions in this area.

\section{A rationale for computer-supported learning}

Initially, computer use in schools was envisioned as that they would 'teach' students; even to the extent that they could replace the teacher with tutorial, and drill and practice software (Chambers and Sprecher 1984; Cox 2012). Fortunately, by the time schools could afford microcomputers the vision had broadened with more open-ended simulation, modelling, and tool software developed (Cox 2012; Glenn and Rakow 1985). For example, by this stage Papert (1980) had introduced Logo and the first word processors appeared.

There has always been a computer literacy rationale, but from the late 1980s, with increasing affordability, the major rationale became to support learning as an educational technology (e.g. DeCorte 1990; Welle-Strand 1991). Much of the research of this period tried to explain why this envisioned potential of the technology was not evident in practice (e.g. Plomp and Pelgrum 1992). Often insufficient access to the technology was cited, and thus the arrival of laptop computers was heralded as a solution to this problem. With this started to emerge evidence of an impact on classroom practices, and ultimately student learning (e.g. Gardner et al. 1993; Walker et al. 2000), including some evidence from my own research (Newhouse 1998). Since then portable computers have become smaller, more powerful and cheaper, as they have converged with mobile phone technologies to become more personal; leading to an aim to have every teacher and student with a device (Cox 2012). This scenario has increasingly been referred to as mobile learning, that can occur anywhere and anytime (e.g. Kearney et al. 2012; Murphy 2011). While most assume that some form of computer support is essential, I believe that a response to portability should be grounded in the rationale for using computer support, irrespective of the form of computer. 
Technology is developed, and/or adopted, to solve problems associated with human need. Therefore, educational technologies should be developed, and/or adopted, to address any of the myriad educational problems with which we are faced. At all levels of decision-making in education (governments, school leaders and teachers) the problem to be addressed should be identified, before the technology is deployed in a learning activity, or new hardware or software is purchased, or policies and plans are drawn up (Ertmer and Ottenbreit-Leftwich 2013; Howland et al. 2012). The question starts in the classroom with the teacher asking, "Am I satisfied with the learning opportunities I can offer my students, are they relevant and engaging?" It is not difficult to argue that in Australian classrooms the response should be in the negative (e.g. Gonski et al. 2011).

For government and school leaders, investment in computer technology comes with an opportunity cost, and thus it is important to consider whether the resulting outputs, such as increased learning outcomes, or better use of teacher and student time, justify the costs of the inputs. What level of optimal investment, justifies a reduced investment in other inputs, such as buildings, books and teachers? More recent research has tended to support the notion that there is a threshold investment in technology, and teacher support, required to deliver significant increased outputs, in whatever way that is measured; from standardised test scores to the qualitative perceptions of stakeholders (e.g. Lei and Zhao 2007; Vanderlinde and van Braak 2010). For example, in their study Lei and Zhao (2007) found that the maximum improvement in Grade Point Average was associated with an average of $3 \mathrm{~h} /$ day of computer use by a student. Clearly this level of use cannot be achieved with investment in only a few computers per classroom.

With every quantum leap in the development in digital technologies, there have been the early adopters, and warnings about what Papert (1987) called, 'technocentric thinking'. Few educators would admit to being technocentric, but it is difficult not to be distracted by the allure of the shiny new gadget, or the clever new piece of software. Rather, educational use of digital technologies should be viewed as one of many mediators in learning processes, and therefore decisions should be based on an understanding of the nature of learning, the learning environment, and the findings of reputable educational research (e.g. Fullan 1995; Howland et al. 2012). Solutions to educational problems should be built on generally accepted expert knowledge about learning and teaching, and this has changed considerably over the past 50 years. Increasingly, social and neuroscience research is supporting theories labelled with constructivism; described as, "that people construct new knowledge and understandings based on what they already know and believe" (Bransford et al. 2000, p. 10).

Learning occurs in a physical and psychosocial 'learning environment' (Fraser 1994), creating what Salomon (1994) refers to as, "a system of interrelated factors that jointly affect learning in interaction" (p. 80). As interactive systems, computers have a place within the relationship milieu of this environment and thus an impact on learning outcomes. As a teacher, I have always found the "sources-ofknowledge" model presented by Pines and West (1986) helpful. It uses a two vines metaphor for the upward spontaneous growth of knowledge frameworks originating from the learner, entangling with the downward imposition of formal knowledge 
frameworks at school. The use of computers to support learning can then be envisaged as providing support for the learner dealing with that entanglement, in what Vygotsky (1978) refers to as the zone of proximal learning. Thus, the term computer supported learning is helpful, and decisions about using computers can be viewed in terms of the overall effectiveness of those supports (Ertmer and Ottenbreit-Leftwich 2013; Howland et al. 2012).

From my early research in the 1990s, I developed a mental model connecting the learning environment with factors affecting the use of computer support (Newhouse 1998). The model starts with the learning environment, and largely plays out through the teacher from beliefs, attitudes and perceptions through to a response and level of facilitation, and then feedback loops back to impact on the environment. The other entities, such as students, and those external to the classroom, act as forces either encouraging or discouraging the use of computer support; what Ertmer and Ottenbreit-Leftwich (2013) refer to as enablers or barriers. The balance of forces determines a type of response from the teacher, which then leads to a level of facilitation of computer support, both in terms of amount of use and the meaningfulness of that use. This level of facilitation is moderated by the size of obstacles or barriers to be overcome, or removed, but is largely dependent on the type of response of the teacher; such as, toleration or investigation.

\section{Providing ubiquitous access}

Portable computing in education has come to mean ubiquitous access to computer processing, software and data (Murphy 2011). Initially the strategy was to carry the hardware, software and data around using a laptop computer, or to carry data on a storage device. Increasingly now the strategy is to access data and/or software through networked servers (the cloud) on a range of devices. Devices may vary substantially in processing power, storage capacity and screen size, but increasingly have the capacity to support similar tasks and to share data (Cox 2012).

The ultimate aim for many educators has been to provide ubiquitous access to adequate computer processing and software, for every student, relevant to their learning needs (Murphy 2011; Pegrum et al. 2013; Rowe 1993). This means that either every student carries a device, or can be given access at school and home through devices stored at those locations. A computer-saturated environment, in which students use portable devices, offers the flexibility within any classroom, or elsewhere, to use any number of devices required, without the need to move to a 'special' environment such as a computer laboratory (e.g. Rowe 1993). This is ideal for the teacher with constructivist intentions, as envisaged by Collis (1989) over 20 years ago, “... every student has his [sic] own portable computer and can access the central resources of the school through any workplace of his choice" (p. 15).

For over 20 years there has been substantial research into portable computing in schools with the first studies to be well documented in the early 1990s; such as, some of the Apple Classroom of Tomorrow projects (Dwyer et al. 1991), the PLAIT project in Northern Ireland (Gardner et al. 1994), and a number in Australian schools (e.g. Rowe 1993; Shears 1995). Increasingly as new types of portable 
computing technologies emerged teachers and researchers investigated their use in the classroom (e.g. Crawford and Vahey 2002).

The pivotal early Australian research was conducted at Melbourne's Methodist Ladies College, with a strategy to change the culture of teaching to be more constructivist in nature (e.g. Loader 1993). A few years later a number of additional schools conducted 'laptop trials' including the first reported instance involving a government school and wireless networking (Narracott 1995). The latter technology provided a basis for some of my research at a primary school (Newhouse 2001).

Within a decade, larger more focused research projects were underway that provided cautiously positive reports; such as, the Anytime Anywhere Learning Program that included a comparative study between 'laptop' and 'non-laptop' schools (Walker et al. 2000). Then in 2002 there was a breakthrough initiative in the USA state of Maine giving all secondary students a notebook computer (Silvernail and Lane 2004). In my own state of Western Australia this encouraged the government to set up the first 1-to-1 program in a public secondary school, and I was given the opportunity of evaluating this initiative over a period of 8 years (Newhouse 2008). And then, from 2008 a 1-to-1 program was implemented for government secondary schools throughout NSW and in many schools in other states in Australia (Howard and Carceller 2010). Although much of the research has been focussed on secondary schools there have been notable examples in primary schools (Rowe 1993; Suhr et al. 2010). Overall, this focus for research now spans about 25 years, and although it has revealed some disappointments and problems, increasingly it has uncovered the benefits of portability (e.g. Shapley et al. 2010b).

In countries such as Australia, for nearly 10 years, it has been realistic to call for every student to have a portable device; in fact the vast majority of senior secondary students already do so. Most research has reported evidence that students like using their own portable devices, and there have been more consistent and compelling reports of positive impacts on learning, beyond just the affect on motivation (e.g. Argueta et al. 2011; Bebell and Kay 2010; Berry and Wintle 2009; Lei and Zhao 2007; Shapley et al. 2010b; Suhr et al. 2010). Naturally, all of the positive impacts found for non-portable computing, such as support for higher-order thinking, collaboration, active learning, productivity, problem-solving and authentic assessment, also apply for portable computing, but tend to be amplified (Drayton et al. 2010; Ertmer and Ottenbreit-Leftwich 2013). For example, I have identified the use of portable computing being associated with substantial increases in the use of the technology for a wider range of activities, with greater focus on the investigation of the real world, increasing student productivity, increasing student engagement, increasing authenticity of assessment, knowledge building, student independence and collaboration (Newhouse 2008; Newhouse and Clarkson 2008). These meaningful uses of the technology for learning are typically associated with more process-oriented rather than content-oriented outcomes, with the flexibility of portable computing leading to support for a wider range of activities implemented in a greater range of ways (e.g. Argueta et al. 2011; Bebell and Kay 2010; Berry and Wintle 2009; Lei and Zhao, 2007; Lowther et al. 2012; Rowe 1993).

Despite the increasingly positive evidence from research, teachers' responses continue to vary from great enthusiasm to hostility, although as the reliability and 
usability of the devices, software and networks have improved, acceptance has increased. Many teachers have found the technology liberating, allowing them to implement the more constructivist pedagogies they have always wanted to use, but found too difficult in the past (Argueta et al. 2011; Becker et al. 1999; Newhouse 2008). Clearly portable computing is a powerful force on teachers encouraging greater facilitation of computer support for learning, while overcoming some barriers (Bebell and Kay 2010; Shapley et al. 2010a). This is not to say that all opposing forces and obstacles disappear.

\section{Obstacles and opposing forces}

Despite increasing realisation of the potential of portable computing, most researchers have still reported a number of barriers (Ertmer and OttenbreitLeftwich 2013). In fact, Hew and Brush (2007) claim to have identified 123 barriers to using computers in schools that they distilled to six categories that concerned: access to resources; teacher knowledge and skills; institutional leadership and operation; teacher attitudes and beliefs; assessment; and curriculum 'culture'. Ertmer and Ottenbreit-Leftwich (2013) identify external and internal barriers that I refer to as obstacles that can be overcome or removed by an external agent, and opposing forces that need an internal change in the teacher. Some early barriers such as high costs of hardware, unreliability, and weight, have diminished (Murphy 2011; Newhouse 2008). From early days some teachers have found the management of the dynamics of the classroom environment difficult (Sandholtz et al. 1992), for some a lack of confidence and technical skills has been a barrier (Gardner et al. 1994; Shapley et al. 2010a), and for many beliefs associated with teacher-centred pedagogies have limited facilitation of computer support (Ertmer and OttenbreitLeftwich 2013; Newhouse 2008). I have classified the barriers as technical, personal experience and beliefs, organisational, and pedagogical.

Technical barriers are disappearing rapidly although it wasn't until the early twenty first century that many were adequately addressed by improvements in hardware and software, and the advent of affordable wireless networking (Cox 2012; Drayton et al. 2010; Newhouse 2001). Greaves and Hayes (2008) reported that robustness and larger screen size were now more important factors than weight, and that battery life was approaching the $5 \mathrm{~h}$ thought necessary. There are often barriers using new technologies in old physical environments such as, inappropriate desks and a lack of power outlets (Hew and Brush 2007). Also most devices are not designed for children to use and therefore are not adequately robust, requiring schools to typically maintain around $10 \%$ of devices as spares (Crawford and Vahey 2002; Newhouse 2008). Further, where devices such as laptops are used in more informal environments, ergonomics is a concern, but this may be addressed by careful design and management of student use of the devices (Straker et al. 2009).

Technical barriers may be dissolving rapidly but unfortunately the same cannot be argued for non-technical barriers such as limited teacher skills and experience, constraining school organization, inflexible curriculum and pedagogy, and unhelpful perceptions, attitudes and beliefs (Ertmer and Ottenbreit-Leftwich 2013). Largely 
these are barriers to any computer use, not just portable devices, and they tend to hark back to the rationale for computer use to support student-centred constructivist pedagogical practices. Hattie (2003) argues that in general the teacher accounts for $30 \%$ of variance in achievement by students, and therefore is the most important factor that can be influenced.

Personal experience and beliefs barriers are related to teacher skills, knowledge, and experience in facilitating computer support for learning (Hew and Brush 2007; Means 2010; Vanderlinde and van Braak 2010). Having student-owned devices has tended to diminish the effect of teacher operational skills (Lowther et al. 2012; Newhouse 2008) although it has always been more likely that teachers with limited skills will feel inadequate and deskilled in computer-supported learning environments (Sandholtz et al. 1992). However, teachers still require skills, knowledge and experience in what more recently Mishra and Koehler (2006) have referred to as TPACK (Technological, Pedagogical and Content Knowledge). That is, the capability to plan and implement computer use to support pedagogical strategies appropriate to convey particular curriculum content. This is critical, no matter how portable the computer technology, although it could be argued that increased portability provides greater flexibility for teachers in developing this capability. These TPACK capability obstacles can be readily addressed through the provision of targeted curriculum and technical professional support (Ertmer and OttenbreitLeftwich 2013). Irrespective of knowledge, skills and experience differences there are typically some teachers who have a more positive active response to the potential of computer support (Hew and Brush 2007). They tend to employ pedagogies, and create learning environments, that demonstrate constructivist-type beliefs (Berry and Wintle 2009; Lowther et al. 2012; Shapley et al. 2010a). Teachers with more instructivist beliefs tend to only facilitate computer use for lower cognitive tasks such as information access and presentation (Drayton et al. 2010; Ertmer and Ottenbreit-Leftwich 2013) and quickly give up when they encounter obstacles (Hew and Brush 2007; Newhouse 1999). Inan and Lowther (2010) estimated that teacher readiness and beliefs explained 0.84 of the variance in 'laptop integration'.

Organisational barriers are external to the teacher; in particular, school leadership, policies, practices and organisation (Hew and Brush 2007; Means 2010; Vanderlinde and van Braak 2010). For example, school leadership may provide all students with portable computers, a high quality networked infrastructure, and "informed and consistent administrative policy" that encourages teachers to try new approaches (Drayton et al. 2010, p. 44). Alternatively a school may have short teaching time periods, isolated teachers, and no computer use policies to guide practice; all of which mitigate against computer support for learning (Gardner et al. 1994). I believe that these are obstacles that are relatively easily removed by school and school system leaders. For example, I have noted the value of a school appointing a 'Curriculum Director' who has the responsibility for supporting teachers in integrating computer support for learning (Newhouse 2012).

Pedagogical barriers concern the relationship between the curriculum and teachers' pedagogical beliefs and practices. We have discussed the link between pedagogy and computer use, however, all aspects of the curriculum may either 
encourage or discourage teachers. For many, computer use is still seen as a dispensable appendage, "outside the curriculum" (Hill et al. 2001, p. 61), and yet initially school leaders aimed to support more open-ended and flexible curriculum (Loader 1993). What teachers believe about the nature of teaching a particular section of the curriculum is likely to influence how, or whether, they use computers in their teaching (Drayton et al. 2010; Hew and Brush 2007). Where a curriculum is very prescriptive, with a focus on discrete bits of content, many teachers will see computer support as unnecessary. This effect is sometimes noticeable in differences in use between subject areas, dictated by subject 'cultures' and assessment requirements (Gardner et al. 1994; Hew and Brush 2007). It is not surprising that the use of computers is minimised where hand-written limited response exams predominate. I have consistently found that where the requirements of paper-based exams predominate teachers are less likely to implement computer support for learning; for example with older and/or higher ability students (Newhouse 1998). I believe that at this time assessment policies and practices form the major remaining obstacles.

\section{Decisions for implementation}

When I started teaching in 1979 at my school I had access to one terminal and modem to connect to a mainframe computer. Today there is a bewildering array of options varying in size, capacity, speed, connectivity and cost. In deciding to implement mobile/portable computing there have been four main interrelated types of decisions to make.

1. The degree of operating environment standardisation.

2. The degree of user control.

3. The degree of hardware and software portability.

4. Ownership.

I believe the third decision type is now just a question of the best way to provide maximum portability to allow students access anywhere-anytime. For example, to what extent should students carry a device with software, such as a netbook or tablet, and to what extent should software and data be located independent of the device, as illustrated through 'cloud computing'? The day of the fixed paradigm where the student comes to the computer system in a laboratory is drawing to a close. There is now ample evidence that portable devices are the best way of providing ubiquitous access that enhances the invisibility of the technology, reduces a techno-centric focus, and better supports constructivist learning environments (e.g. Berry and Wintle 2009; Murphy 2011).

The first two types of decisions typically contrast computer system security and maintenance against computer-supported learning, and are a source of obstacles. Those responsible for the former tend to advocate maximum standardisation and minimum user control, while those responsible for the latter want maximum flexibility and independence. However, in the extremes a system with which nothing can be done is very secure and easy to maintain, while a system with no consistency 
or controls becomes chaotic and unusable. The control end of this debate is often associated with a 'thin client' model, in some ways harking back to the dumb terminal with which I started (e.g. Hew and Brush 2007). Proponents of the use of highly standardised and centralised systems tend to borrow arguments from other industries. These typically fail to account for the substantial differences between the core teaching and learning functions of education, and the purely administrative functions. Thus, a balance is needed, to provide a system with enough user control and connectability to permit students and teachers to choose from a large range of options for computer support for learning.

Finally, there is the question of ownership that is related to the first two decision types. As the devices become increasingly portable and comprehensive, and less expensive, it is almost certain that they will be 'owned' by students and this will almost certainly encourage more meaningful use (Shapley et al. 2010b). There are three main concerns within the ownership question: cost, security, and personal identity.

The cost of portable computers will always be more than an equivalent nonportable system. However, it has become more reasonable to ask governments, sponsors or parents to buy systems. Ultimately what is important is whether each student has his/her own computer, not who pays for it.

The security, both physical and logical, is of concern for all stakeholders. The physical security of personally owned systems becomes largely the responsibility of the user, but the logical security is largely the school's responsibility. The research is mixed on physical security with the outcome largely dependent on school management processes, but it is certainly less of a concern where the student owns the device. Logical security may present an increase in cost for school network maintenance but this is offset by the reduced responsibility for maintaining the devices (Newhouse 1998). The much improved quality and availability of sophisticated network control tools have also readily addressed these concerns.

How children interact within their environments impacts on their sense of personal identity, including when using technology, and is critical for their healthy development. Personal computer systems have evolved to allow more personalisation and they are most productively used when they become a 'part' or extension of the user (Rowe 1993). However, this will reduce the capacity of teachers and school support to provide operational help and thus students need to become more independent users (Donovan et al. 2010). Traditionally the use of personally owned devices at school has not commenced below about 10 years of age with class sets of devices used with younger students.

Does it matter which device is chosen? Traditionally much time has been spent debating this choice. I have argued that decision-making should start with learning, not with the devices, and yet ultimately a student needs a device. Unfortunately, or fortunately, there is such a range of devices varying in size, power, storage, operation, appearance, cost and connectedness. What components of a system do students need to carry? Is a small mobile device that plugs into other devices and networks adequate, or should it at least include some applications software and data storage? The growth of 'cloud computing' applications and storage has supported small mobile devices plugging into larger systems. At the same time many mobile 
devices are used independently with small custom-designed applications (apps) for specific tasks. Ultimately it is not the particular device that matters, rather how its use supports a learning environment and types of learning activities (Ertmer and Ottenbreit-Leftwich 2013). For example, with younger children a robust, small, and easy to manipulate device is required, perhaps a tablet kept at school. Older children need access to more sophisticated and complex software tools, so perhaps netbooks that connect to larger screens and input/output devices, carried between home and school. The reality is that increasingly most devices can do most things a student would need to do and therefore there may be many devices that are equally as appropriate. This is at the heart of the bring your own device (BYOD) strategy.

\section{Conclusion}

After over 20 years of evidence that has increasingly indicated the success of providing ubiquitous computing access through the use of portable digital devices, there is a basis for widespread implementation in schools. If we want to create more student-centred learning environments based on constructivist understandings, and if we want to empower children as learners, then we know we can use such devices to support these aims; assuming we also have reliable networks, adequate technical support, appropriate software, informed and effective school leadership, relevant curriculum, well-prepared teachers, and connected local communities. As for calculators in the 1980s, the reducing cost of the devices is increasingly suggesting that students should own their device(s). The perennial questions about which type of device and what components should be portable should be the last questions addressed after the vision and plan for how the technologies will be used to support learning is agreed upon.

Reflecting on my own struggles from 1979 to provide the technology that I have found so empowering, to empower my students, I have so often felt that we were near to the tipping point that would transform the learning experiences for children in our schools. Each time I have seen glimpses in some classrooms of what could be, but the big ship of schooling has hardly deviated. If turning the ship was just dependent on having the technology available then we are way past that point, however, it is more likely to depend on our collective will to evolve the appropriate pedagogical understandings amongst our teachers, school leaders and communities. Only then will we get the return on many decades of investment in digital technologies in schools.

\section{References}

Argueta, R., Huff, J., Tingen, J., \& Corn, J. O. (2011). Laptop initiatives: Summary of research across six states. Raleigh, NC: Friday Institute for Educational Innovation, North Carolina State University.

Bebell, D., \& Kay, R. (2010). One to one computing: A summary of the quantitative results from the Berkshire wireless learning initiative. Journal of Technology, Learning, and Assessment, 9(2), 5-59. 
Becker, H. J., Ravitz, J. L., \& Wong, Y. T. (1999). Teacher and teacher-directed student use of computers and software, Irvine, California. Retrieved Aug 27, 2013, from http://www.crito.uci.edu/tlc/findings/ ComputerUse/html/startpage.htm.

Berry, A. M., \& Wintle, S. E. (2009). Using laptops to facilitate middle school science learning: The results of hard fun. Gorham, ME: Center for Education Policy, Applied Research, and Evaluation, University of Southern Maine.

Bransford, J. D., Brown, A. L., \& Cocking, R. R. (Eds.). (2000). How people learn: Brain, mind, experience, and school. Washington, DC: National Academy Press.

Chambers, J. A., \& Sprecher, J. W. (1984). Computer-assisted instruction: Current trends and critical issues. In D. F. Walker \& R. D. Hess (Eds.), Instructional software (pp. 6-19). Belmont: Wadsworth.

Collis, B. (1989). Using information technology to create new educational situations. Higher Education Policy, 2(4), 63-70.

Cox, M. J. (2012). Formal to informal learning with IT: Research challenges and issues for e-learning. Journal of Computer Assisted learning, 29(1), 85-105.

Crawford, V., \& Vahey, P. (2002). Palm Education Pioneers Program March 2002 Evaluation Report. Menlo Park, CA: SRI International.

DeCorte, E. (1990). Learning with new information technologies in schools: Perspectives from the psychology of learning and instruction. Journal of Computer Assisted learning, 6, 69-87.

Dede, C. (2008). Theoretical perspectives influencing the use of information technology in teaching and learning. In B. K. J. Voogt (Ed.), International handbook of information technology in primary and secondary education (Vol. 20, pp. 43-62). New York: Springer Science + Business Media LLC.

Donovan, L., Green, T., \& Hartley, K. (2010). An examination of one-to-one computing in the middle school: Does increased access bring about increased student engagement? Journal of Educational Computing Research, 42(4), 423-441.

Drayton, B., Falk, J. K., Stroud, R., Hobbs, K., \& Hammerman, J. (2010). After installation: Ubiquitous computing and high school science in three experienced, high-technology schools. Journal of Technology, Learning, and Assessment, 9(3), 4-56.

Dwyer, D. C., Ringstaff, C., \& Sandholtz, J. H. (1991). Changes in teachers' beliefs and practices in technology-rich classrooms. Educational Leadership, 48(8), 45-52.

Ertmer, P. A., \& Ottenbreit-Leftwich, A. (2013). Removing obstacles to the pedagogical changes required by Jonassen's vision of authentic technology-enabled learning. Computers and Education, 64, $175-182$.

Fraser, B. J. (1994). Research on classroom and school climate. In D. Gabel (Ed.), Handbook of research on science teaching and learning (pp. 493-541). New York: Macmillan.

Fullan, M. (1995). The school as a learning organization: Distant dreams. Theory into Practice, 34(4), 230-235.

Gardner, J., Morrison, H., \& Jarman, R. (1993). The impact of high access to computers on learning. Journal of Computer Assisted learning, 9(1), 2-16.

Gardner, J., Morrison, H., Jarman, R., Reilly, C., \& McNally, H. (1994). Learning with portable computers. Computers in Education, 22(1/2), 161-171.

Glenn, A. D., \& Rakow, S. J. (1985). Computer simulations: Effective teaching strategies. The Computing Teacher, 12(5), 58-59.

Gonski, D., Boston, K., Greiner, K., Lawrence, C., Scales, W., \& Tannock, P. (2011). Review of Funding for Schooling-Final Report. Canberra: Department of Education, Employment and Workplace Relations.

Greaves, T. W., \& Hayes, J. (2008). America's Digital Schools 2008: The six trends to watch. Encinitas, CA: Greaves Group.

Hattie, J. (2003). Teachers make a difference: What is the research evidence? In Paper presented at the ACER Annual Conference, Building Teacher Quality, Melbourne, Australia: Australian Council for Educational Research.

Hew, K. F., \& Brush, T. (2007). Integrating technology into K-12 teaching and learning: current knowledge gaps and recommendations for future research. Educational Technology Research and Development, 55, 223-252.

Hill, J., Reeves, T. C., Grant, M., \& Wang, S. (2001). The impact of portable technologies on teaching and learning: Year two report. Athens, GA: Athens Academy, University of Georgia.

Howard, S., \& Carceller, C. (2010). The impact of the digital education revolution in NSW government schools: Baseline data. Sydney: NSW Department of Education and Training. 
Howland, J. L., Jonassen, D., \& Marra, R. M. (2012). Meaningful learning with technology (4th ed.). Boston, MA: Pearson Education Inc.

Inan, F. A., \& Lowther, D. L. (2010). Laptops in the K-12 classrooms: Exploring factors impacting instructional use. Computers and Education, 55, 937-944.

Kearney, M., Schuck, S., Burden, K., \& Aubusson, P. (2012). Viewing mobile learning from a pedagogical perspective. Research in Learning Technology, 20(1), 14406.

Lei, J., \& Zhao, Y. (2007). Computer uses and student achievement: A longitudinal study. Computers and Education, 49, 284-296.

Loader, D. (1993). Reconstructing an Australian school. The Computing Teacher, 20(7), 12-15.

Lowther, D. L., Inan, F. A., Ross, S. M., \& Strahl, J. D. (2012). Do one-to-one initiatives bridge the way to 21st century knowledge and skills? Journal of Educational Computing Research, 46(1), 1-30.

Means, B. (2010). Technology and education change: Focus on student learning. Journal of Research on Technology in Education, 42(3), 285-307.

Mishra, P., \& Koehler, M. J. (2006). Technological pedagogical content knowledge: A framework for teacher knowledge. Teachers College Record, 108(6), 1017-1054.

Murphy, G. D. (2011). Post-PC devices: A summary of early iPad technology adoption in tertiary environments. e-Journal of Business Education \& Scholarship of Teaching, 5(1), 18-32.

Narracott, I. (1995). Laptops in school: Response of teachers, students and parents. In L. Shears (Ed.), Computers and schools (pp. 50-66). Camberwell, VIC: The Australian Council for Educational Research.

Newhouse, C. P. (1998). Teachers' responses and classroom learning environments associated with student access to portable computers. Ph.D., Curtin University of Technology, Perth, WA.

Newhouse, C. P. (1999). Examining how teachers' adjust to the availability of portable computers. Australian Journal of Educational Technology, 15(2), 148-166.

Newhouse, C. P. (2001). Wireless portable technology unlocks the potential for computers to support learning in primary schools. Australian Educational Computing, 16(2), 6-13.

Newhouse, C. P. (2008). Transforming schooling with support from portable computing. Australian Educational Computing, 23(2), 19-23.

Newhouse, C. P. (2012). Effective school leadership for return on investment in ICT. In C. P. Newhouse \& J. Pagram (Eds.) conference proceedings, Australian Computers in Education Conference (pp. 1-7). Perth, WA: Australian Council for Computers in Education.

Newhouse, C. P., \& Clarkson, B. D. (2008). Creating contexts for learning with ICT in schools. In N. Yelland, G. A. Neal, \& E. Dakich (Eds.), Rethinking education with ICT: new directions for effective practice (pp. 57-78). Rotterdam: Sense Publishers.

Papert, S. (1980). Mindstorms: Children, computers and powerful ideas. Brighton, SX: The Harvester Press Ltd.

Papert, S. (1987). Computer criticism vs. technocentric thinking. Educational Researcher, 16(1), 22-30.

Pegrum, M., Oakley, G., \& Faulkner, R. (2013). Schools going mobile: A study of the adoption of mobile handheld technologies in Western Australian independent schools. Australasian Journal of Educational Technology, 29(1), 66-81.

Pines, A. L., \& West, L. H. T. (1986). Conceptual understanding in science learning: An interpretation of research within a sources-of-knowledge framework. Science Education, 70(5), 583-604.

Plomp, T., \& Pelgrum, W. J. (1992). Restructuring of schools as a consequence of computers. International Journal of Educational Research, 19, 185-195.

Rowe, H. A. H. (1993). Learning with personal computers. Hawthorn: Australian Council for Educational Research.

Salomon, G. (1994). Differences in patterns: Studying computer enhanced learning environments. In S. Vosniadou, E. DeCorte, \& H. Mandl (Eds.), Technology-based learning environments (pp. 79-88). Heidelberg: Springer.

Sandholtz, J. H., Ringstaff, C., \& Dwyer, D. C. (1992). Teaching in high-tech environments: Classroom management revisited. Journal of Educational Computing Research, 8(4), 479-505.

Shapley, K., Sheehan, D., Maloney, C., \& Caranikas-Walker, F. (2010a). Effects of technology immersion on teachers' growth in technology competency, ideology, and practices. Journal of Educational Computing Research, 42(1), 1-33.

Shapley, K., Sheehan, D., Maloney, C., \& Caranikas-Walker, F. (2010b). Evaluating the implementation fidelity of technology immersion and its relationship with student achievement. Journal of Technology, Learning, and Assessment, 9(4), 1-2. 
Shears, L. W. (Ed.). (1995). Computers and schools. Camberwell, VIC: The Australian Council for Educational Research.

Silvernail, D. L., \& Lane, M. M. (2004). The impact of maine's one-to-one laptop program on middle school teachers and students. Gorham: Maine Education Policy Research Institute, University of Southern Maine.

Straker, L., Maslen, B., Burgess-Limerick, R., \& Pollock, C. (2009). Children have less variable postures and muscle activities when using new electronic information technology compared with old paperbased information technology. Journal of Electromyography and Kinesiology, 19, 132-143.

Suhr, K. A., Hernandez, D. A., Grimes, D., \& Warschauer, M. (2010). Laptops and fourth-grade literacy: Assisting the jump over the fourth-grade slump. Journal of Technology, Learning, and Assessment, 9(5), 1-45.

Vanderlinde, R., \& van Braak, J. (2010). The e-capacity of primary schools: Development of a conceptual model and scale construction from a school improvement perspective. Computers and Education, $55,541-553$.

Vygotsky, L. S. (1978). Mind in society: The development of higher psychological processes. Cambridge: Harvard University Press.

Walker, L., Rockman, S., \& Chessler, M. (2000). A more complex picture: Laptop use and impact in the context of changing home and school access. San Francisco, CA: Rockman et al.

Welle-Strand, A. (1991). Evaluation of the Norwegian program of action: The impact of computers in the classroom and how schools learn. Computers and Education, 16(1), 29-35.

Weston, M. E., \& Bain, A. (2010). The end of techno-critique: The naked truth about 1:1 laptop initiatives and educational change. Journal of Technology, Learning, and Assessment, 9(6), 1-25.

C. Paul Newhouse is an Associate Professor in educational computing at Edith Cowan University in Perth, Western Australia. He is currently the Director of the Centre for Schooling and Learning Technologies (CSaLT) in the School of Education. He was fortunate to begin his teaching career in an innovative government secondary school in Western Australia and this encouraged him to conduct research in schools and then work with pre-service and practicing teachers at two universities. His aim has been to improve the opportunities for all children to develop as decision-making, empowered, responsible, relational citizens through engaging and relevant schooling. As a result his focus is on integrating ICT to support learning, particularly as applied to portable computing, assessment and curriculum development in technology education. 